\title{
Déjà vu All Over Again: Elliott's Critique of Eyewitness Experts*
}

\author{
Saul M. Kassin, † Phoebe C. Ellsworth, $\ddagger$ and Vicki L. Smith§
}

Echoing McCloskey and Egeth (1983), and motivated by Kassin, Ellsworth, and Smith's (1989) survey of 63 eyewitness experts, Elliott (1993) recently attacked the use of psychological experts on eyewitness testimony. There are two principal shortcomings of this critique. First, it misrepresents the eyewitness literature and the experts who use it. Second, it merely parrots complaints of the past. The same old arguments are made about the lack of sufficient research evidence, the standards by which experts should conduct their affairs, and the impact of it all on the jury. Perhaps the field needs periodic prodding and consciousness-raising on this issue, but there is very little in this critique that is imaginative or new compared to those that preceded it. And what is new is based on an irresponsible review of the literature.

\section{Elliott's View of the Eyewitness Literature}

Before criticizing a body of research, one should carefully review the literature. Meta-analysis would be ideal and a qualitative summary would be acceptable as well, but a narrow and selective citation of studies is not. Any scientific phenomenon can be debunked by citing a null result or an isolated failure to replicate, or by narrowing the range of studies that qualify for inclusion. So what?

Elliott's central point is that the phenomena about which eyewitness experts are willing to testify are not reliable, or are too complex to be summarized in a

\footnotetext{
* Correspondence should be addressed to Saul M. Kassin at the Department of Psychology, Bronfman Science Center, Williams College, Williamstown, Massachusetts 01267.

+ Williams College.

$\ddagger$ University of Michigan.

$\S$ Northwestern University.
} 
single statement. The concern is valid, but the methods used to demonstrate the problem are not. To begin with, Elliott spends the most time "exposing" the effects of showups, stress, weapon focus, the forgetting curve, and unconscious transference. It is noteworthy that these phenomena were ranked for reliability by the experts as only 8th, 13th, 17th, 9th, and 7th, respectively, on our list of 21 items. With two briefly described exceptions (the postevent information effect, the accuracy-confidence correlation), the phenomena that our experts judged most reliable (i.e., the effects of question wording and lineup instructions) are not addressed. So, how does this piecemeal critique shed new light on the eyewitness expert controversy? It does not. Let us get specific.

\section{Showups}

Elliott begins by noting that although $83 \%$ of experts said showups increase the risk of misidentification, a recent paper by Gonzalez, Ellsworth, and Pembroke (1993) reported the opposite effect. Of course, this paper was not published at the time the survey was conducted, which was in May of 1986. Indeed, of the studies Elliott cites in an effort to discredit our experts, $80 \%$ postdate the survey. In light of this subsequent research, would experts now reconsider some of their prior assessments? Probably they would - which is precisely the reason that we argued in our 1989 paper that the survey needs periodic updating.

Our second reaction to Elliott's citation of the Gonzalez et al. (1993) study is that he got it wrong. He claims the study demonstrated that showups decrease the risk of false positive identifications. The authors of the study went to great pains to avoid oversimplifying their results in this way, and their data do not support such a conclusion. To summarize, Gonzalez et al. (1993) noted that "Our results provide no evidence that one-person showups are more suggestive than full lineups. Instead they suggest that lineups may provide less protection against misidentification and showups less danger of misidentification than is commonly believed" (p. 536). They did not find that showups were better than lineups. To characterize the results in this manner is to mislead by exaggeration.

\section{Stress}

Next Elliott points out that (a) the effects of stress (specifically, the notion that high levels of arousal lower identification accuracy) are not reliable enough to serve as a basis for expert testimony, despite the fact that (b) this is "the second most frequently testified-to subject among the experts" (p. 426). Elliott is right about the inconsistencies in the stress literature. But so were our experts. That is why, out of the 21 items included in our survey, stress was ranked as 13th on the question of whether it is reliable enough to be presented in court. So why beat on a dead horse? As far as this topic being the second most talked about, Elliott should have added that a meager $38 \%$ of the experts had actually testified on stress, presumably, in some cases, to say that the effect is not reliable. As our results made clear, testimony about a phenomenon is not always in favor of that 
phenomenon. We will get back to this point when we discuss the value of having experts shatter the misconceptions held by jurors.

\section{Weapon Focus}

Elliott next complains that experts were testifying about the weapon focus effect (the tendency for the presence of a weapon to diminish identification accuracy) before there was sufficient evidence for it. Look at the numbers in our results, however, and you will find that of all the items in our survey, weapon focus ranked 17th in perceived reliability and was the subject of past testimony for only $27 \%$ of the experts. After our survey was completed, several additional studies were conducted and published, and-as summarized in a recent meta-analysis (Steblay, 1992) - these studies provided clear support for the weapon focus effect. For experts who testified that the presence of a weapon could impair memory for faces (and we do not know if this is what they did say), these new findings vindicate their prior testimony. Rather than concede this data-driven point, however, Elliott, chooses to refocus the terms of the debate. Now we are told that the effect may well be reliable, but that the presence or absence of a weapon accounts for only a small percentage of the total variance in identification performance. To our knowledge, no expert has ever claimed that the mere presence of a weapon, or any other single factor for that matter, is sufficient on its own to discredit an identification. Yet Elliott asks, "What would the Kassin et al. (1989) respondents now say?" The answer, we think, is simple: If the body of research indicates that the effect is consistent but small, knowledgeable experts would probably say just that.

\section{Unconscious Transference}

Critical of the imprecise term "unconscious transference," Elliott next goes on to dispute this phenomenon. Forget the term and its shortcomings, however. What our experts responded to was the statement that, "Eyewitnesses sometimes identify as a culprit someone they have seen in another situation or context." Eighty-four percent agreed with this general statement, no doubt familiar not only with the Buckhout (1974) and Loftus (1976) papers cited by Elliott, but with Brown, Deffenbacher, and Sturgill (1977), and Gorenstein and Ellsworth (1980). Since this survey, a study by Brigham and Cairns (1988) has provided additional support for this phenomenon. Does Elliott truly believe that testimony on this item currently rests on a weak foundation? Call it what you like, get beyond the term "transference," and examine the pages of cognitive psychology journals, and you will find strong, far-reaching, and profound support for the idea. Experiments on implicit memory (Schacter, 1992; Tulving \& Schacter, 1990), retention without awareness (Roediger, 1990), familiarity without awareness (Mandler, 1980), the false fame effect (Jacoby, Kelley, Brown, \& Jasechko, 1989), failures in reality monitoring (Johnson \& Raye, 1981) as well as source monitoring (Johnson, Hashtroudi, \& Lindsay, 1993), all converge on the same point: Dissociations between recognition and awareness of context are common. In light of these results, the experts in our sample were quite reasonable in their assessments. 


\section{The Forgetting Curve}

Elliott next addresses the Ebbinghaus forgetting curve, specifically, the statement that "The rate of memory loss for an event is greatest right after the event, and then levels off over time." He notes that this was the sixth most testified-to phenomenon on our list, yet once again neglects to point out that only $27 \%$ of the experts had testified on it. Is the forgetting curve irrelevant to eyewitness testimony? Elliott says that the human face has special properties as a stimulus, and he may be right. But the statement experts reacted to, and presumably the content of their testimony on this issue, concerns memory for events, not faces. On that issue, Ebbinghaus's (1885) discovery also holds for memories of real events (e.g., Bahrick, 1984). Should negative results be reported in future research, the opinions of the experts would likely change as well.

\section{Additional Issues}

After focusing on items that were not highly ranked by our experts, Elliott critiqued the postevent information effect ("Eyewitness testimony about an event often reflects not only what they actually saw but information they obtained later on") and the accuracy-confidence correlation ("Eyewitness confidence is not a good predictor of his or her identification accuracy")-items ranked by the experts as third and fourth in reliability, respectively.

Elliott describes postevent information results as "complex" and "mixed." $\mathrm{He}$ is certainly right about the complexity of the conceptual issues concerning human memory that are raised by this research and about the limits of the effect (e.g., it is stronger for peripheral details and is affected by the relative timing of the manipulation and test; these points were made in the initial paper by Loftus, Miller, \& Burns, 1978). Elliott is quite wrong, however, to suggest that the phenomenon itself is not reliable. Numerous investigators in different laboratories continue to replicate the effect (Belli, 1992; Chandler, 1991; Tversky \& Tuchin, 1989). Even McCloskey and Zaragoza (1985), who devised a modified test procedure to discredit Loftus's theory, replicated the effect using her choice task. Researchers may disagree on whether misinformation impairs memory, but there is no question that it can impair a witness's testimony.

Turning to the accuracy-confidence correlation, Elliott (1993) writes, "Psychologists in the eyewitness field tend to write about the relation of confidence to accuracy as if the idea of a positive relation between them were one of the great myths of out time, one which we as experts are uniquely equipped to dispel" ( $p$. 431). In this statement, Elliott is wrong on two counts. First, the idea that confidence is a good predictor of eyewitness accuracy is a myth-not only on a between-subjects basis, but within subjects as well (Smith, Kassin, \& Ellsworth, 1989). Second, laypeople do believe that confidence predicts accuracy (Kassin \& Barndollar, 1992) and assert these beliefs in mock jury deliberations (Hastie, 1980). Elliott seems not to realize that in recasting this literature, he departs from the combined assessment of 63 other knowledgeable experts, $87 \%$ of whom rated this lack of correlation as reliable enough to present in court. We cannot review this literature in depth at this point, but the body of evidence-not isolated 
studies-provides substantial support for the opinions rendered by the experts (Wells, 1993; Wells \& Murray, 1984).

\section{Elliott's Characterization of the Experts}

We agree with Elliott on two points: that experts should adopt a conservative standard, and that their testimony should be balanced and qualified as necessary. Indeed, the purpose of our survey was to advance these goals by providing empirical guidance to judges, lawyers, and the experts themselves.

In many ways, Elliott misrepresented our results, and thus the behavior of expert witnesses. He makes much of what he calls the "top 10 list"-the ten topics on which our experts testified most often. What he does not also mention is that for most of these topics, $70 \%$ said they had never testified. Even for the top item (the postevent information effect), only $41.3 \%$ had testified. And what do the experts say once they are in court? In the survey, we did not ask whether the experts endorsed the statements on our list in their testimony, so there is no basis for Elliott to believe that those who testify misrepresent the literature or recite like automatons the simple and unqualified statements contained in our survey questions. He complains that experts were willing to offer testimony about phenomena that they themselves rated as low in reliability (e.g., stress), but he neglects the fact that they may have testified to say just that.

Elliott does not acknowledge that the experts said they were as willing to testify for the prosecution as for the defense, and for both sides in civil cases. $\mathrm{He}$ also fails to mention that more experts reported that they had refused to testify at least once than said they had testified at least once. Many of the reasons the reluctant experts gave were reasons that Elliott would approve: They feared they would not be permitted to qualify their answers, or felt they had nothing useful to say, or doubted their own expertise in a particular case. Of course, there are "hired guns" in psychology, as in medicine, physics, and other disciplines, who disgrace the field by their willingness to say anything for the right price, but there is no reason to assume that this is characteristic of eyewitness experts in general. Elliott criticizes experts for "simplifying matters so much when they speak to juries" (p. 427), claiming that they "amplify small signals" (p. 431) when giving "confident testimony" (p. 435), and that "we continue to say things we ought not to say (we overgeneralize) and not to say those things we ought to say (we underqualify)" (p. 435). What empirical evidence does he present to support these strong charges? It would seem prudent before making such accusations to make an effort to examine the actual content of expert testimony, lest one be accused as well of making unqualified claims.

Elliott's numerous pleas for experts to refrain from making bald statements, to acknowledge the limitations of the research they describe, and to be forthright about negative results ("if they are included, however, much of the force of the typical defense testimony will be lost", p. 429), are so naive as to lead us to wonder if Elliott understands what goes on in a courtroom. He seems to assume that experts walk a royal red carpet to the witness stand, take the oath, and deliver the lecture of their choice to the jury - without constraint, without interruption, 
without cross examination, and without opposing witnesses (some of the very experts who took part in our survey). Clearly, that is not an accurate portrayal of expert testimony, and clearly there is no reason to believe that the 63 experts in our survey routinely overstate their claims, or even testify in the same direction.

\section{What Juries Need to Hear}

We conducted our survey to provide the psychological and legal communities with a better estimate of "general acceptance" (the Frye test standard) than a haphazard list of publications, prior judicial opinions, or worse, the in-court statements of one or two battling experts. Although we provided an improved estimate of consensus, we ourselves criticized the Frye test as a criterion for the admissibility of expert testimony. Instead we suggested using a Bayesian analysis to judge the extent to which expert testimony assists the trier of fact. Elliott either missed or chose to ignore this key point. We argued that expert testimony is worthy of admissibility only when a finding is generally accepted by scientists but not sufficiently known by jurors or when it is not generally accepted by scientists but assumed to be true as a matter of common sense. To focus only on expert opinion is to miss half the point. What would Elliott say if it turned out that many jurors believe that stress creates reliable eyewitness memories-a belief that many do hold (Hastie, 1980; Kassin \& Barndollar, 1992), and one that contradicts the weight of evidence? In instances like this, we believe that jurors are better off knowing that the research is inconclusive than allowing their misconceptions to distort their judgments.

\section{CONCLUSION}

Elliott's closing section entitled "guidelines" rehashes the parameters of the Egeth and McCloskey (1983) and Loftus (1983) debate on the question of when research evidence is sufficient to take to court. His point is driven by the assertion that despite hundreds of eyewitness experiments conducted in recent years, and despite related theories and research in memory and cognition, "we do not know very much about the factors contributing to eyewitness accuracy" (p. 432). If we know so little, then large numbers of psychologists and students have wasted many hours and squandered millions of taxpayer dollars. So, why draw the bright line at the courtroom door? And assuming that Elliott does not single out eyewitness researchers as less competent than their counterparts in other areas of psychology (maybe he does), then he must take an equally dim view of those who intervene in the promotion of health, educational reform, discrimination in the workplace, and other important domains of application.

Our survey involved 63 eyewitness experts, of whom Elliott was one the signed his questionnaire). A majority of the respondents disagreed with him on many points, which illustrates the reason that such surveys are useful. In court, Professor Elliott might well convince a judge that his views reflect the weight of expert opinion. Our research indicates, however, that his views are not represen- 
tative of those found in the scientific community. Both under Frye and the newly announced standard in Daubert v. Merrell DOW Pharmaceuticals (1993), general acceptance is an important criterion, one by which idiosyncratic views are subject to challenge. If Elliott has hard data (we do not) which indicate that eyewitness experts consistently "overgeneralize" and "underqualify," then he should present these data rather than make the kinds of frivolous assertions he so laments in the rest of us.

\section{REFERENCES}

Bahrick, H. P. (1984). Semantic memory content in permastore: Fifty years of memory for Spanish learned in school. Journal of Experimental Psychology: General, 113, 1-35.

Belli, R. F., Windschitl, P. D., McCarthy, T. T., \& Winfrey, S. E. (1992). Detecting memory impairment with a modified test procedure: Manipulating retention interval with centrally presented event items. Journal of Experimental Psychology: Learning, Memory, and Cognition, 18, 356367.

Brigham, J. C., \& Cairns, D. L. (1988). The effect of mugshot inspections on eyewitness identification accuracy. Journal of Applied Social Psychology, 18, 1394-1410.

Brown, E. L., Deffenbacher, K. A., \& Sturgill, W. (1977). Memory for faces and the circumstances of encounter. Journal of Applied Psychology, 62, 311-318.

Buckhout, R. (1974). Eyewitness testimony. Scientific American, 231, 23-31.

Chandler, C. C. (1991). How memory for an event is influenced by related events: Interference in modified recognition tests. Journal of Experimental Psychology: Learning, Memory, and Cognition, $17,115-125$.

Cutler, B. L., Penrod, S. D., \& Dexter, H. R. (1990). Juror sensitivity to eyewitness identification evidence. Law and Human Behavior, 14, 185-191.

Daubert v. Merrell Dow Pharmaceuticals, Inc., 61 LW 4805 (1993).

Elliott, R. (1993). Expert testimony about eyewitness identification. Law and Human Behavior, 17, 423-437.

Gonzalez, R., Ellsworth, P. C., \& Pembroke, M. (1993). Response biases in lineups and showups. Journal of Personality and Social Psychology, 64, 525-537.

Gorenstein, G. W., \& Ellsworth, P. C. (1980). Effect of choosing an incorrect photograph of a later identification by an eyewitness. Journal of Applied Psychology, 65, 616-622.

Hastie, R. (1980). From eyewitness testimony to beyond reasonable doubt. Paper presented at the Annual Meeting of the Law and Society Association and the Research Committee on Sociology of Law of the International Sociological Association, Madison, Wisconsin.

Jacoby, L. L., Kelley, C. M., Brown, J., \& Jasechko, J. (1989). Becoming famous overnight: Limits on the ability to avoid unconscious influences of the past. Journal of Personality and Social Psychology, 56, 326-338.

Johnson, M. K., Hashtroudi, S., \& Lindsay, D. S. (1993). Source monitoring. Psychological Bulletin, $114,3-28$.

Johnson, M. K., \& Raye, C. L. (1981). Reality monitoring. Psychological Review, 88, 67-85.

Kassin, S. M., \& Barndollar, K. A. (1992). The psychology of eyewitness testimony: A comparison of experts and prospective jurors. Journal of Applied Social Psychology, 22, 1241-1249.

Kassin, S. M., Ellsworth, P. C., \& Smith, V. L. (1989). The "general acceptance" of psychological research on eyewitness testimony: A survey of the experts. American Psychologist, 44, 10891098.

Loftus, E. F. (1976). Unconscious transference in eyewitness identification. Law and Psychology Review, 2, 93-98.

Loftus, E. F. (1983). Silence is not golden. American Psychologist, 65, 9-15. 
Loftus, E. F., Miller, D. G., \& Burns, H. J. (1978). Semantic integration of verbal information into visual memory. Journal of Experimental Psychology: Human Learning and Memory, 4, 19-31.

Mandler, G. (1980). Recognizing: The judgment of previous occurrence. Psychological Review, 87, 252-271.

McCloskey, M., \& Egeth, H. (1983). Eyewitness identification: What can a psychologist tell a jury? American Psychologist, 38, 550-563.

McCloskey, M., \& Zaragoza, M. (1985). Misleading postevent information and memory for events: Arguments and evidence against memory impairment hypotheses. Journal of Experimental Psychology, 114, 3-18.

Roediger, H. L., III. (1990). Implicit memory: Retention without remembering. American Psychologist, 45, 1043-1056.

Schacter, D. L. (1992). Understanding implicit memory: A cognitive neuroscience approach. American Psychologist, 47, 559-569.

Smith, V. L., Kassin, S. M., \& Ellsworth, P. C. (1989). Eyewitness accuracy and confidence: Withinversus between-subjects correlations. Journal of Applied Psychology, 74, 356-359.

Steblay, N. M. (1992). A meta-analytic review of the weapon-focus effect. Law and Human Behavior, $16,413-424$.

Tulving, E., \& Schacter, D. L. (1990). Priming and human memory systems. Science, 247, 301-306.

Tversky, B., \& Tuchin, M. (1989). A reconciliation of the evidence on eyewitness testimony: Comments on McCloskey and Zaragoza. Journal of Experimental Psychology, 118, 86-91.

Wells, G. L. (1993). What do we know about eyewitness identification? American Psychologist, 48, 553-571.

Wells, G. L., \& Murray, D. M. (1984). Eyewitness confidence. In G. Wells \& E. Loftus (Eds.), Eyewitness testimony: Psychological perspectives. (pp. 155-170) New York: Cambridge University Press. 